\title{
GAMBARAN PENGETAHUAN, SIKAP, DAN KELUHAN TENTANG MENSTRUASI DIANTARA REMAJA PUTERI
}

\author{
${ }^{1}$ Tetti Solehati, ${ }^{2}$ Mira Trisyani, ${ }^{3}$ Cecep Eli Kosasih \\ ${ }^{1,2,3}$ Fakultas Keperawatan Universitas Padjajaran \\ Email: tsh_tetti@yahoo.com
}

\begin{abstract}
Abstrak
Latar Belakang: Menstruasi merupakan hal yang biasa terjadi pada perempuan yang sudah memasuki masa remaja remaja. Sebagian remaja memiliki keluhan-keluhan saat menstruasi terjadi. Tujuan penelitian untuk mengetahui gambaran pengetahuan, sikap dan keluhan remaja puteri mengenai menstruasi. Metode: Desain penelitian deskriptif kuantitatif.. Jumlah sampel sebanyak 100 santriwati. Penelitian dilakukan di pondok pesantren Al-Musaddadiyah Garut pada tahun 2017. Instrumen yang digunakan terdiri dari data keluhan saat menstruasi, pengetahuan, dan sikap yang dibuat berdasarkan referensi terkait dan telah dilakukan uji konten dan uji reabilitas serta uji validitas. Data dianalisis dengan analisis univariat. Hasil penelitian menunjukan bahwa lebih dari setengah responden sebanyak 69 orang (69\%) mengalami keluhan pegal dan sebagian responden sebanyak 56 orang (56\%) mengalami dismenorhoe saat menstruasi.Pada variabel pengetahuan dan sikap tentang perawatan saat menstruasi ditemukan bahwa semua responden sebanyak 100 orang (100\%) berpengetahuan buruk dan sebagian besar responden sebanyak 78 orang (78\%) memiliki sikap tidak mendukung terhadap perawatan saat menstruasi . Kesimpulan: para remaja cenderung mengalami keluhan saat menstruasi, serta memiliki pengetahuan buruk dan sikap tidak mendukung tentang perawatan saat menstruasi.
\end{abstract}

Kata kunci: Keluhan Menstruasi, Pengetahuan, Remaja, Sikap.

\begin{abstract}
Background: Menstruation is common in women who are in their teenage years. Some teens have complaints when menstruation occurs. The study aimed to describe the knowledge, attitudes, and complaints about menstruation of female teenagers. Method: The research design was quantitative descriptive. Number of sample consisted 100 santriwati. The study conducted at boarding school Al-Musaddadiyah Garut in 2017. The instruments consisted of complaints data on menstruation, knowledge, and attitudes. It made based on relevant references and have tested for content validity and reliability test. Data were analyzed by univariate analysis. Results: The results showed that 69 people (69\%) had stiff complaints and 56 people (56\%) had dysmenorrhoe during menstruation. The knowledge and attitude about menstrual care, all respondents were $100(100 \%)$ in poorly knowledge and 78 people (78\%) have a non-supportive attitude. Conclusion: Teenagers tend to experienced complaints during menstruation, as well as having poor knowledge and have a nonsupportive attitude about the treatment during menstruation. Suggestion: based on the results of the study for the existence of teenager health education program that explains about menstruation and handling, it needs involving nurses in cooperation with teacher of Pondok Pesantren continuously.
\end{abstract}

Keywords: Menstrual Complaint, Knowledge, Teenagers, Attitude 


\section{PENDAHULUAN}

Menstruasi merupakan kejadian fisiologis bagi perempuan yang sudah remaja, dalam hal ini hormon-hormon reproduksi mereka sudah mulai bekerja. Menstruasi merupakan sebuah indikator kematangan seksual pada remaja putri (Gustina \& Djannah, 2015). Akan tetapi, sayangnya tidak semua remaja dapat melalui masa menstruasi dengan biasa, karena banyak juga yang mengalami keluhan-keluhan pada saat menstruasi berlangsung. Keluhankeluhan yang mungkin dapat dialami remaja saat menstruasi berlangsung seperti gejala gatal-gatal disekitar vulva, iritasi pada area genital serta adanya rasa perih, vaginitis, vulpovaginitis, flour albus, bau yang tidak menyenangkan (Baradero, 2007; Leppert \& Peipert, 2004). Keluhan-keluhan tersebut akan semakin bertambah apabila remaja mengalami masalah dalam menstrual hygienenya. Oleh karena itu diperlukan perawatan diri saat menstruasi, baik untuk mengatasi keluhan-keluhan maupun untuk kesehatan reproduksinya itu sendiri. Perawatan diri saat menstruasi memiliki tujuan, menurut Adika (2013) dan Uzochukwu et al (2009), tujuan dari perawatan diri saat menstruasi adalah agar terpeliharanya kebersihan dan kesehatan individu selama masa menstruasi tersebut. Menurut McCaleb \& Cull (2000) mengatakan bahwa keadaan yang buruk dalam kebersihan genital dan perawatan diri seseorang saat menstruasi merupakan salah satu faktor terjadinya morbiditas pada remaja. Hal ini tentu akan mengganggu pada masalah kesehatan reproduksi remaja. Perawatan diri saat menstruasi meliputi beberapa hal, menurut Poureslami \& Ashtiani (2002), Santina, Wehbe, Ziade, \& Nehme (2013) perawatan diri tersebut meliputi frekuensi mengganti pakaian dan celana dalam, mengganti pembalut, membasuh area genitalia, kegiatan aktivitas normal sehari- hari, personal hygiene, asupan nutrisi, dan penggunaan obat yang diresepkan dokter.

Perawatan diri saat menstruasi pada seseorang dipengaruhi oleh beberapa faktor, antara lain faktor pengetahuan dan sikap (Green dalam Notoatmojo, 2007). Banyak penelitian yang menyebutkan bahwa pengetahuan dan sikap dapat memengaruhi perilaku seseorang dalam kehidupan sehari-harinya. Salah satunya adalah penelitian Umairoh (2014) pada siswi SMP di Surabaya yang menemukan bahwa pengetahuan dan sikap memengaruhi perilaku perineal hygiene. Perawatan diri yang kurang selama menstruasi bisa diakibatkan oleh karena kurangnya kesadaran akibat oleh kurangnya informasi yang memadai yang diperoleh para remaja puteri mengenai bagaimana menjaga kebersihan saat menstruasi. Selain itu, masih banyaknya anggapan di berbagai negara bahwa topik menstruasi masih menjadi hal yang tabu untuk dibahas, malah dianggap sebagai sesuatu yang memalukan. Mitos-mitos yang ada di masyarakat kebanyakan juga memiliki implikasi yang negatif pada kesehatan perempuan, salah satunya pada kebersihan menstruasi mereka (Rajakumari, 2015).

Sosiolkultural yang berbeda-beda juga akan mempengaruhi perawatan diri remaja putri saat menstruasi. Penelitian Karout (2015) pada siswi keperawatan di Arab Saudi ditemukan bahwa mereka sebagian besar kurang memiliki pengetahuan dan keyakinan yang benar mengenai menstruasi. Di Indonesia sendiri perawatan diri selama menstruasi masih banyak dipengaruhi oleh keyakinan sosiolkultural. Penelitian Roasih (2009) pada masyarakat etnis budaya Jawa ditemukan bahwa jika remaja putri sudah mengalami menarche, para ibu selalu menasihati anaknya agar minum jamu kapur sirih untuk menghindari keluhan gatal-gatal di daerah kelamin. 
Kurangnya informasi pada remaja puteri tentang perawatan menstruasi untuk menghindarkan keluhan-keluhan selama menstruasi menyebabkan masalah kenyamanan selama remaja mengalami menstruasi. Gharoro (2013) mengatakan bahwa banyak remaja perempuan kurang memahami menstruasi akibat dari kurangnya perolehan informasi yang memadai terkait isu perawatan diri terkait menstruasi. Masih banyaknya sikap orang tua dan masyarakat yang kurang terbuka dalam mendiskusikan perawatan diri saat menstruasi dengan remaja tersebut bisa menjadi penghalang bagi remaja untuk mendapatkan hak informasi yang tepat. Pemahaman yang kurang memadai tentang perawatan diri saat menstruasi tersebut dapat menyebabkan remaja puteri berisiko mengalami masalah reproduksi. Menurut Sari (2012), Berdasarkan Badan Pusat Statistik Indonesia (2008) ditemukan 43,3 juta jiwa remaja berperilaku tidak sehat yang dapat menimbulkan keputihan.

Kabupaten Garut merupakan kabupaten dengan jumlah remaja yang banyak, termasuk remaja puterinya. Remaja di Kabupaten Garut menurut Badan Koordinasi Keluarga Berencana Nasional (BKKBN) Provinsi Jawa Barat memiliki risiko terhadap masalah kesehatan reproduksi akibat kurang terpaparnya informasi kesehatan reproduksi. Prevalensi remaja yang terkena infeksi saluran reproduksi (ISR) yang melakukan pemeriksaan ke pelayanan kesehatan di Kabupaten Garut pada tahun 2014 sebanyak 27 orang meningkat menjadi 39 orang pada tahun 2015. Data tersebut belum menckup para remaja yang tidak datang ke pelayanan kesehatan sehingga masalah kesehatan reproduksinya tidak akan terdeteksi oleh pelayanan kesehatan. Kondisi masalah remaja seperti ini terlihat seperti fenomena gunung es, dalam hal ini data yang terlihat hanya sedikit sementara kasus yang sebenarnya terjadi kemungkinan banyak (Dinkes Garut, 2015).

Garut terkenal sebagai kota santri, hal ini terjadi karena di Garut banyak pesantren yang didirikan. Salah satunya adalah Pondok Pesantren Al-Musaddadiyah yang merupakan pondok pesantren terbesar yang ada di Kecamatan Tarogong Kidul (BPS Garut, 2013). Penelitian di pesantren ini menarik karena pesantren memiliki aturan-aturan yang di ambil berdasarkan kaidah-kaidah agama, salah satunya adalah kebersihan pribadi. Tetapi budaya di pesantren memiliki aturan yang ketat yang tidak memungkinkan siswa untuk bertanya tentang masalah pribadi terkait dengan masalah reproduksinya. BKKBN (dalam Fitriyah, Indriani dan Sulistyorini, 2013) menyatakan bahwa kepercayaan, sikap, dan nilai yang ada di pesantren serta anggapan bahwa pesantren sebagai pendidikan alternatif ideal bagi remaja menjadikan kebudayaan yang ada di pesantren berbeda dengan budaya masyarakat pada umumnya diluar pesantren. Lingkungan pesantren yang cenderung ketat memungkinkan remaja pesantren berisiko mengalami kesulitan dalam penyelesaian masalah akibat akses untuk mendapatkan informasi kesehatan yang tertutup, salah satunya masalah perawatan diri saat mentruasi. Hal tersebut memungkinkan adanya keluhan-keluhan selama menstruasi.

\section{METODE PENELITIAN}

Desain penelitian menggunakan deskriptif kuantitatif. Populasi dalam penelitian ini adalah seluruh remaja di Pondok Pesantren Al-Musaddadiyah Garut berjumlah 100 santriwati dengan sample total sampling. Instrument penelitian terdiri atas : (A) data keluhan saat menstruasi. (B) Kuesioner 
pengetahuan. (C) Kuesioner sikap. Analisis data menggunakan analisis univariat berupa persentase. Peneliti dilakukan di Pondok Pesantren Al-Musaddadiyah Garut pada Mei - Desember tahun 2016 dengan terlebih dahulu telah mendapatkan persetujuan etik dari BANGKESBANGPOL Kabupaten Garut no 072/336 BAKESBANGPOL/2016.

\section{HASIL PENELITIAN}

Tabel 1.

Distribusi Frekuensi Karakteristik Demografi Responden Tahun 2016 ( $n=100)$

\begin{tabular}{lcc}
\hline \multicolumn{1}{c}{ Karakteristik } & $\begin{array}{c}\text { Frekuensi } \\
(\mathbf{f})\end{array}$ & $\begin{array}{c}\text { Presentase } \\
(\mathbf{\%})\end{array}$ \\
\hline Keluhan saat & & \\
menstruasi & & \\
$\quad$ Mual & 2 & 2 \\
Susah tidur & 7 & 7 \\
Pegal & 69 & 69 \\
Bau tak sedap & 27 & 27 \\
Gatal & 27 & 27 \\
Iritasi & 16 & 16 \\
Kecemasan & 11 & 11 \\
Dismenorhoe & 56 & 56 \\
Pusing & 15 & 15 \\
\hline
\end{tabular}

Dari tabel 1 di atas diperoleh bahwa lebih dari setengah responden sebanyak 69 orang $(69 \%)$ mengalami keluhan pegal dan hampir setengah responden sebanyak 56 orang (56 $\%)$ mengalami dismenorhoe saat menstruasi.

Tabel 2.

Distribusi Frekuensi Pengetahuan dan Sikap Tentang Perawatan Diri Saat Menstruasi Responden Tahun $2016(n=100)$

\begin{tabular}{lcc}
\hline Variabel & $\begin{array}{c}\text { Frekuensi } \\
(\mathbf{f})\end{array}$ & $\begin{array}{c}\text { Presentase } \\
(\boldsymbol{\%})\end{array}$ \\
\hline Pengetahuan & & \\
Baik & 0 & 0 \\
Buruk & 100 & 100 \\
\hline Sikap & & \\
Mendukung & 22 & 22 \\
Tidak & 78 & 78 \\
mendukung & & \\
\hline
\end{tabular}

Dari tabel 1 tersebut, diperoleh bahwa seluruh responden memiliki tingkat pengetahuan buruk sebanyak 100 orang (100\%). Dilihat dari variable sikap, sebagian besar responden sebanyak 78 orang (78 \%) memiliki sikap tidak mendukung dalam perawatan diri saat menstruasi.

\section{PEMBAHASAN}

Berdasarkan hasil penelitian, diperoleh bahwa sebagian responden mengalami keluhan pegal dan mengalami dismenorhoe saat menstruasi. Pada penelitian ini juga ditemukan seluruh responden memiliki pengetahuan yang buruk mengenai perawatan diri selama menstruasi. Menurut Brunner (dalam Mubarak 2011), proses pengetahuan terdiri dari tiga aspek, yaitu proses mendapat informasi, proses transformasi, dan proses evaluasi. Pengetahuan atau kognitif merupakan domain yang sangat penting dalam membentuk tindakan seseorang. Jika seseorang memperoleh pendidikan lebih tinggi, maka semakin mudah pula seseorang tersebut memperoleh informasi, dan pengetahuan yang dimiliki akan semakin banyak (Mubarak, 2011). Buruknya pengetahuan yang dimiliki responden dimungkinkan karena informasi yang didapat selama ini hanya sampai pada tingkatan pengetahuan yang pertama yaitu tahu (know), kemungkinan para responden belum sampai memahami atau bahkan mengaplikasikan pengetahuan yang mereka dapat ke dalam kehidupan mereka sehari-hari. Hal ini terbukti dengan banyaknya reponden yang menjawab salah pada pertanyaanpertanyaan subvariabel definisi menstruasi, fisiologi menstruasi, dan gangguan dalam menstruasi. Hasil penelitian mengenai pengetahuan perawatan diri saat menstruasi yang buruk ini sesuai dengan hasil penelitian dari Kusrandini (2010), yaitu hanya 12,07\% yang memiliki pengetahuan dikategorikan 
baik mengenai Menstrual Hygiene pada remaja putri di SMP Al-Falah Dago Kota Bandung.

Berdasarkan hasil penelitian, sikap para responden sebagian besar (78\%) cenderung kurang mendukung dalam perawatan diri selama menstruasi ini. Menurut Azwar (2007) ada beberapa faktor yang mempengaruhi sikap antara lain, pengalaman pribadi, pengaruh orang lain yang dianggap penting, pengaruh kebudayaan, media massa, lembaga pendidikan, dan faktor emosional. Pengetahuan buruk yang dimiliki responden dapat mempengaruhi sikap mereka. Sikap yang mendukung tidak hanya diperoleh dari pengetahuan saja, namun diperlukan proses yang meliputi kemauan untuk melakukan suatu objek dan internalisasi (Azwar, 2011). Selain pengetahuan, kemungkinan faktor kebudayaan pun dapat berpengaruh dalam perawatan diri selama menstruasi, seperti masih diyakininya beberapa mitos-mitos saat menstruasi, sebagai contoh adalah tidak boleh keramas saat menstruasi ataupun membatasi aktivitas sehari-hari saat menstruasi. Faktor-faktor tersebut dapat membuat sikap responden menjadi tidak mendukung dalam perawatan diri saat menstruasi.

Perlu adanya program pemberian edukasi yang memadai oleh tim kesehatan dalam hal ini perawat, baik kepada remaja puteri, ibu mereka, dan para gurunya. Ibu dan guru adalah dua sosok yang cenderung lebih dekat dengan remaja puteri dibanding dengan sosok yang lainnya. Penelitian Solehati (2015) pada remaja puteri menemukan bahwa $82 \%$ remaja puteri lebih banyak mendapatkan informasi kesehatan dari ibunya. Informasi yang akurat dan memadai akan meningkatkan pemahaman dan sikap remaja puteri sehingga dapat meminimalkan keluhan-keluhan saat terjadinya menstruasi pada remaja puteri.
Dengan demikian remaja memiliki reproduksi yang sehat.

\section{KESIMPULAN}

Berdasarkan penelitian yang telah dilakukan mengenai perilaku perilaku perawatan diri selama menstruasi pada siswi di pondok pesantren Al-Musaddadiyah Garut, dapat disimpulkan bahwa para remaja cenderung mengalami keluhan saat menstruasi, serta memiliki pengetahuan dan sikap yang buruk tentang perawatan saat menstruasi.

\section{UCAPAN TERIMA KASIH}

Ucapkan terima kasih kami sampaikan kepada pihak LPPM Universitas Padjajaran yang telah membiayai penelitian ini melalui skema Hibah penelitian HPKRD, serta tidak lupa juga kepada semua pihak yang telah berpartisipasi dalam penyelesaian penelitian ini.

\section{REFERENSI}

Adika, V. O., Ayinde, M. O., \& Jack-Ide I.O. (2013). Self care practices of menstrual hygiene among adolescents school going girls in Ammasoma Community, Bayelsa State. International Journal of Nursing and Midwifery. 5(5):99-105

Baradero, Dayrit, dan Siswadi. 2007. Seri Asuhan Keperawatan Klien Gangguan Sistem Reproduksi dan Seksualitas. Jakarta: EGC.

BPS. 2013. Data Penduduk Kecamatan Tarogong Kidul Kabupaten Garut. Garut: BPS

Fitriyah, N., Indriani, D., \& Sulistyorini, Y. 2013. Riwayat Kesehatan Reproduksi Remaja Santri. journal.unair.ac.id. diakses tanggal 10Februari 2016.

Gharoro, L. A. (2013). Menstrual hygiene practices among junior secondary school students in Benin City. Journal of Educational and Social Research, 129. 
Gustina, E. \& Djannah, S.N. 2015. Sumber Informasi Dan Pengetahuan Tentang Menstrual Hygiene Pada Remaja Putri. KEMAS jurnal kesehatan masyarakat. 10 (2): 147-152

Leppert \& Peipert, 2004). Primary care for women. Philadelphia, PA; London : Lippincott Williams \& Wilkins

McCaleb A, Cull VV (2000). Socio-cultural influences and self care practices of middle adolescents. J. Pediatr. Nurs. l5(1):30-35.

Mubarak, W. I. (2011). Promosi Kesehatan untuk Kebidanan. Jakarta: Salemba Medika.

Rajakumari G, A. (2015). A S tudy on Knowledge regarding Menstrual Hygiene among Adolescent School Girls. Global Journal of Current Research, 111-116.
Santina, T., Wehbe, N., Ziade, F. M., \& Nehme, M. (2013). Assessment of Beliefs and Practices Relating to Menstrual Hygienen of Adolescent Girls in Lebanon. International Journal of Health Sciences and Research, 7588.

Sari, I.P., Firani, K.F. \& Yuliatun, L. (2013). Pengaruh Pendidikan Kesehatan tentang Menstruasi terhadap Perubahan Perilaku Menstrual Hygiene Remaja Putri untuk Pencegahan Infeksi Saluran Reproduksi (ISR). BIMIKI. 2(1):11-18.

Solehati, T. Ermiati, Trisyani, M. \& Hermayanti, Y. 2017. Hubungan Sumber Informasi dan Usia Remaja Puteri dengan Perilaku Perawatan Diri saat Menstruasi. Jurnal Keperawatan Padjajaran. 5(2): 145-154. 